\title{
LA INVISIBILIZACIÓN DEL MOVIMIENTO ZAPATISTA ACTUAL EN EL TURISMO DE LOS ALTOS DE CHIAPAS ${ }^{1}$
}

\author{
Patricia Viera-Bravo* \\ Universidad Nacional Autónoma de México. \\ https://orcid.org/0000-0001-5833-7640 \\ Álvaro López López** \\ Universidad Nacional Autónoma de México. \\ https://orcid.org/0000-0003-0719-1316
}

\section{RESUMEN}

En este artículo se analizan los principales factores que han operado en la invisibilización del Ejército Zapatista de Liberación Nacional (EZLN) en los circuitos turísticos de Los Altos de Chiapas, mismos que se han beneficiado de la notoriedad mundial lograda por el levantamiento de 1994. Se plantean como factores relevantes el cerco militar y en las comunicaciones impuesto por el Estado mexicano como parte de su estrategia contrainsurgente, así como la producción social de nuevos espacios centrales como parte de la propuesta autonómica zapatista, que se articulan en relaciones alternativas entre comunidades y con redes de apoyo externas.

Palabras clave: turismo; contrainsurgencia; Chiapas; comunidad; espacio social.

\section{Disregarding the Zapatista Movement in the development of tourism at Los Altos de} Chiapas

Fecha de recepción: 28 de noviembre de 2018.

Fecha de aceptación: 22 de abril de 2019.

1 Este artículo se deriva del Proyecto "Turismo oscuro en México: un enfoque interdisciplinario desde las ciencias sociales", Proyecto de Ciencia Básica (239653) del Consejo Nacional de Ciencia y Tecnología (CONACYT).

Se agradece, en forma especial, la contribución de María de Lourdes Godínez Calderón por el diseño y la elaboración de la cartografía.

* Instituto de Investigaciones Económicas, Universidad Nacional Autónoma de México. Circuito Mario de la Cueva. Ciudad de la Investigación en Humanidades. Ciudad Universitaria C.P. 04510 Coyoacán. CIUDAD DE MÉXICO.E-mail: patriciaviera@gmail.com

** Instituto de Geografía, Universidad Nacional Autónoma de México. Circuito de la Investigación Científica, Ciudad Universitaria C.P. 04510. Coyoacán. CIUDAD DE MÉXICO. E-mail: lopuslopez@yahoo.com.mx 


\begin{abstract}
This article analyzes the main factors at work in the erasure of the Ejército Zapatista de Liberación Nacional (EZLN) from the tourist circuits of Los Altos de Chiapas, a region that gained worldwide notoriety after the indigenous uprising of January 1, 1994. An evaluation of both the Zapatista autonomic proposals and the State's counterinsurgency measures is carried out, including the effects of the military and communications encirclement imposed by the Mexican State, and the social production of new central spaces, as part of alternative community projects with external support networks.
\end{abstract}

Keywords: tourism; counterinsurgency; Chiapas; community; social space.

\title{
1. INTRODUCCIÓN
}

Desde los años cincuenta del siglo pasado, en que el turismo mexicano se insertó en el mercado global, el gobierno mexicano ha buscado posicionar entre sus destinos turísticos al estado de Chiapas-región del sureste del país, fronteriza con Guatemala y con alta marginación socioeconómica (Figura 1) - fundamentalmente por sus atractivos naturales y arqueológicos. A pesar de los distintos esfuerzos y recursos destinados para el fomento al turismo, el nombre de Chiapas fue realmente posicionado alrededor del mundo por el levantamiento en armas del Ejército Zapatista de Liberación Nacional (EZLN), a partir $1^{\circ}$ de enero de 1994 . La coyuntura que provocó este alzamiento indígena estuvo marcada por las reformas estructurales neoliberales y la entrada en vigor del entonces llamado Tratado de Libre Comercio de América del Norte (TLCAN). Sumado a la histórica explotación y marginación por parte de las élites dominantes hacia los pueblos indígenas de Los Altos de Chiapas y de la Selva Lacandona, arrastró a estos últimos a una "lógica de la desesperación" (Le Bot, 1997:114).

Entonces, los mismos pueblos que constituían uno de los mayores "atractivos turísticos" de la región, se levantaron en armas contra el Estado mexicano, explicitando en la "Primera Declaración de la Selva Lacandona" sus demandas de "trabajo, tierra, techo, alimentación, salud, educación, independencia, libertad, democracia, justicia y paz" (EZLN, 1994a:s/p). Además del municipio de San Cristóbal de las Casas, el EZLN tomó las cabeceras municipales de Las Margaritas, Altamirano, Ocosingo, Huixtán y Chanal. Pero la necesidad de que el gobierno mexicano tuviera que salvaguardar una imagen de estabilidad frente a sus nuevos socios comerciales del TLCAN, y la presión ejercida por la sociedad civil que apoyaba las demandas exigidas por EZLN, llevó al establecimiento de un cese al fuego unilateral, luego de doce días en los que no se ha podido determinar el número de víctimas (Leyva Solano y Burguette, 2007; Pitts, 1996; Le Bot, 1997; Castro Soto, 2000).

Entonces, los mismos pueblos que constituían uno de los mayores "atractivos turísticos" de la región, se levantaron en armas contra el Estado mexicano, explicitando en la "Primera Declaración de la Selva Lacandona" sus demandas de "trabajo, tierra, techo, alimentación, salud, educación, independencia, libertad, democracia, justicia y 
paz" (EZLN, 1994a:s/p). Además del municipio de San Cristóbal de las Casas, el EZLN tomó las cabeceras municipales de Las Margaritas, Altamirano, Ocosingo, Huixtán y Chanal. Pero la necesidad de que el gobierno mexicano tuviera que salvaguardar una imagen de estabilidad frente a sus nuevos socios comerciales del TLCAN, y la presión ejercida por la sociedad civil que apoyaba las demandas exigidas por EZLN, llevó al establecimiento de un cese al fuego unilateral, luego de doce días en los que no se ha podido determinar el número de víctimas (Leyva Solano y Burguette, 2007; Pitts, 1996; Le Bot, 1997; Castro Soto, 2000).

\section{Figura 1}

\section{SAN CRISTÓBAL DE LAS CASAS EN EL CONTEXTO DE LA REGIÓN DE LOS ALTOS DE CHIAPAS}

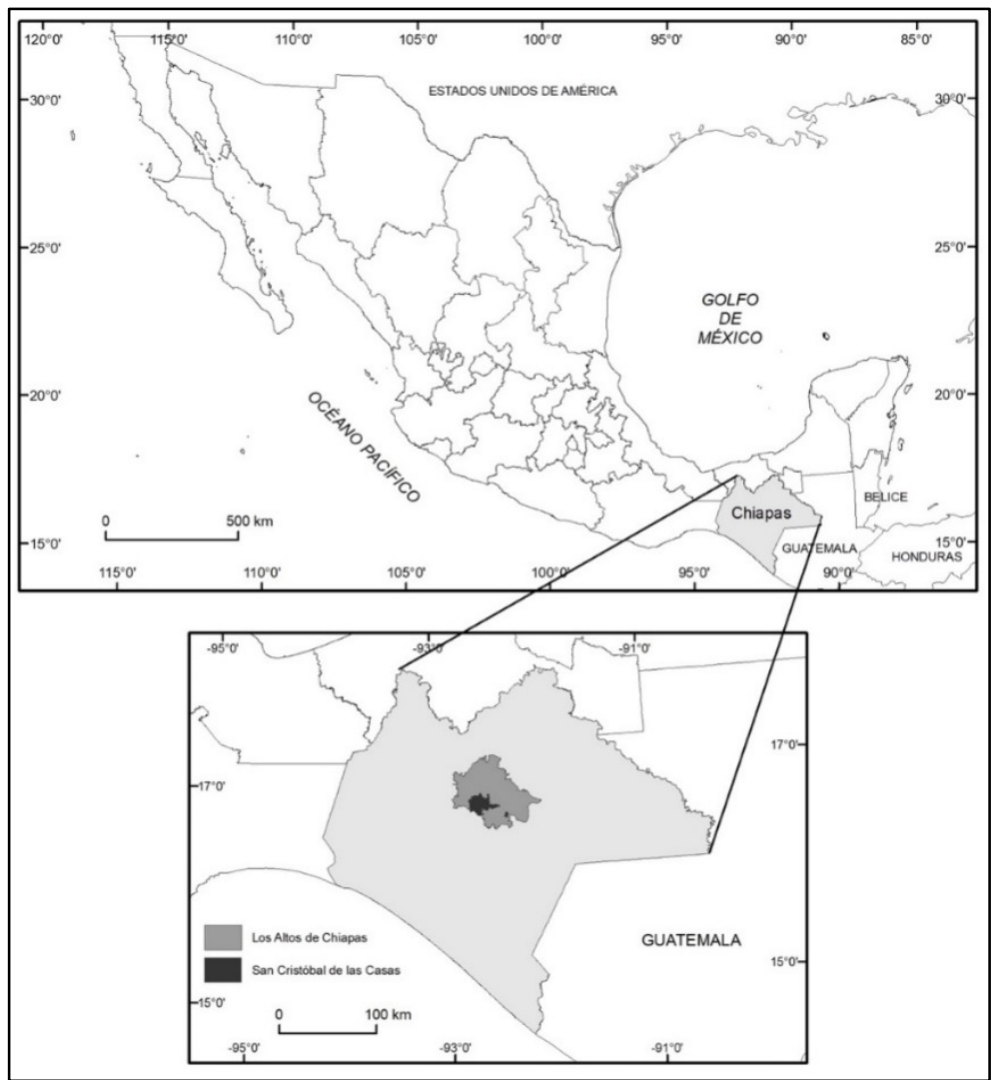

Fuente: Elaborado por María de Lourdes Godínez Calderón, 2018.

El gran impacto que provocó el levantamiento del EZLN en la escena internacional, atrajo - más allá de los contingentes militares y representantes del gobierno mexicano que llegaron desde el primer momento - a periodistas y observadores de derechos humanos 
(DDHH) de todo el mundo, muchos de los cuales entraron en calidad de turistas, al tiempo que los turistas tradicionales se comenzaron a retirar. La ciudad de San Cristóbal de las Casas, como centro neurálgico de la región de Los Altos de Chiapas (Figura 1), pronto se convirtió en el núcleo de operaciones del conflicto indígena, pues su ubicación estratégica e infraestructura urbana permitió recibir a los nuevos visitantes (Garza Tovar y Sánchez Crispín, 2015). Desde entonces, la dinámica turística de San Cristóbal de las Casas y de sus alrededores se fue transformando y creciendo a raíz de la nueva demanda por servicios hoteleros y turísticos. Sin embargo, este desarrollo turístico fue aumentando, al mismo tiempo de una especie de silenciamiento sobre lo ocurrido en torno al zapatismo, por los factores que serán ampliamente analizados en los siguientes apartados.

Este artículo tiene el objetivo de explorar los factores que han relegado la presencia del zapatismo a los márgenes de los principales circuitos turísticos de la ciudad de San Cristóbal de las Casas, pese a que por varios años ha sido el propio EZLN el que mantuvo en la escena turística nacional e internacional a esta ciudad (mucho más que las propias iniciativas gubernamentales). Entre los factores externos más relevantes, se plantea el cerco militar y mediático que, como parte de las políticas contrainsurgentes, censuró la difusión de información del movimiento insurgente y ocultó la represión hacia las bases de apoyo del EZLN, llegando a perseguir y criminalizara los observadores de DDHH que denunciaban violaciones en la zona de conflicto. Entre los factores internos, se analiza el foco que el EZLN ha puesto en la necesidad de mantener el apoyo externo, principalmente internacional, en detrimento de la visibilidad del proyecto social y político zapatista en el contexto local y regional. Además, la nueva reconfiguración del territorio en conflicto, propia de la transformación de las relaciones sociales en torno al levantamiento indígena, corre el riesgo de generar nuevas marginalidades alrededor de las centralidades emergentes del poder autónomo, que podrían ser distanciadas del tipo de turista interesado en acercarse al movimiento (turista revolucionario y turista solidario, entre otros).

A fin de cubrir el objetivo de esta investigación, el desarrollo del artículo está planteado en los siguientes cuatro apartados: después de presentar los principales aspectos metodológicos, se exponen los fundamentos teóricos para comprender cómo se ha producido el espacio social en la región de Los Altos de Chiapas, en torno a la brecha de desigualdad social entre ladinos e indígenas; en los dos apartados siguientes, se expone cómo la participación del Estado, en su estrategia contrainsurgente, contribuyó a nulificar la presencia del zapatismo dentro de las dinámicas del turismo local, con acciones contra la observación internacional y con el redireccionamiento del desarrollo turístico; y, en el último apartado se analizan factores internos del fenómeno estudiado, como el foco en la generación de nuevas centralidades territoriales y en mantener el apoyo externo.

\subsection{Aspectos Metodológicos}

Esta investigación tiene como base una metodología de triangulación en turismo que, en palabras de Decrop (1999:158), está “basada en la analogía del triángulo” pues supone que en torno a un centro de reflexión gravitan al menos tres fuentes metodológicas diferentes e independientes. Esta metodología permite procesar la información obtenida de procedencias variadas, a fin de probar su fiabilidad al contrastarlas. En primer lugar, se 
hizo una revisión bibliográfica de las discusiones teóricas generales que forman parte de este trabajo, además del rescate de informes y datos estadísticos generados por instituciones oficiales mexicanas como la Secretaría de Turismo de Chiapas (SECTUR-Chiapas) o el Instituto Nacional de Geografía y Estadística (INEGI), del cual se consultaron los Anuarios estadísticos y geográficos del estado de Chiapasentre 1984 y 2017, específicamente las cifras disponibles en "Servicios de alojamiento temporal y de preparación de alimentos y bebidas" del municipio de San Cristóbal de las Casas.

Para la elaboración de las fuentes primarias se realizaron dos fases de trabajo de campo —en julio de 2016 y entre mayo y octubre de 2017 - en los que se utilizaron métodos cualitativos, como la observación participante y la entrevista, principalmente en San Cristóbal de las Casas y sus alrededores. La observación participante se realizó en tres de los niveles planteados por Spradley (1980): participación pasiva en los principales circuitos de San Cristóbal de las Casas y espacios zapatistas, como el Centro indígena de Capacitación Integral (CIDECI) (festivales CompArte 2016 y 2017, reuniones del Congreso Nacional Indígena y sesiones del Seminario Semanal); participación moderada en distintos tours (al centro de la ciudad, a pueblos indígenascomo Zinacantán y San Juan Chamula, a las Lagunas de Montebello y a la Selva Lacandona); y participación activa en cursos de capacitación para Observadores de DDHH y participación en una Caravana de Observación a Cruztón.

Se realizaron 28 entrevistas semiestructuradas a diferentes actores vinculados a los procesos analizados: en el sector turístico privado se hicieron ocho entrevistas (cuatro a empresarios, tres a guías y otra a un encargado de personal); en el sector turístico público se entrevistaron a seis funcionarios de SECTUR-Chiapas (cinco de Tuxtla Gutiérrez y uno de la oficina de San Cristóbal de las Casas); en la academia se realizaron cinco entrevistas (dos a investigadores expertos y tres a acádemicos testigos en la zona del periodo analizado); otras cinco entrevistas se hicieron en el área de ONG y observación de DDHH; una entrevista conjunta con los tres miembros de la Junta de Buen Gobierno (JBG) de Oventik; y una entrevista a uno de los periodistas que cubrió el levantamiento zapatista en San Cristóbal de las Casas. Además, se realizó un sondeo entre los turistas nacionales y extranjeros sobre su nivel de simpatía y conocimiento del EZLN, en distintos puntos turísticos de la ciudad - principalmente, en el andador turístico de la calle Real de Guadalupe (Figura 2) - , tanto en 2016 como en 2017.

A esta investigación se suman otras observaciones simples realizadas en fechas anteriores a esta investigación: en enero y febrero del 2000, con el contacto con observadores internacionales y misioneros diocesanos en comunidades indígenas desplazadas; en agosto de 2013, se participó en la Escuelita Zapatista; en 2015, en mayo se asistió al Seminario de Pensamiento Crítico frente a la Hidra Capitalista y en agosto se realizó una visita guiada para conocer el funcionamiento interno del CIDECI.

Uno de los principales obstáculos metodológicos fue la desconfianza de los diversos sujetos contactados para entregar información u opiniones personales sobre el conflicto y el rol del Estado en el fenómeno analizado, entendiéndose porque los autores no pertenecen a la región, y por un tema de seguridad, sobre todo, en el caso de los observadores de DDHH. Sin embargo, esta barrera logró flanquearse por el método de muestreo de bola de nieve (Noy, 2008). 


\section{Figura 2 \\ ANDADOR TURÍSTICO DE REAL DE GUADALUPE, SAN CRISTÓBAL DE LAS CASAS}

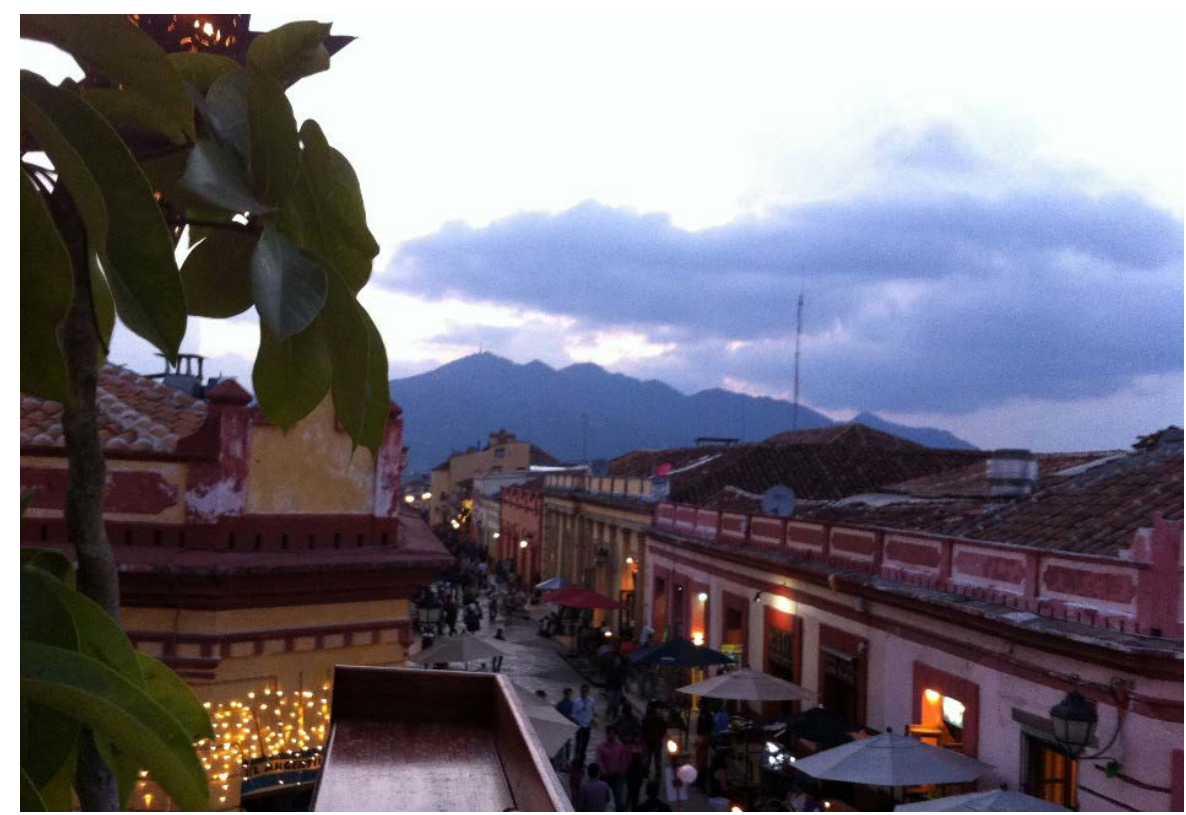

Fuente: fotografía de Patricia Viera-Bravo, 2015.

\section{LA DESIGUALDAD EN LA PRODUCCIÓN DEL ESPACIO EN LOS ALTOS DE CHIAPAS}

Para abordar el análisis del fenómeno de invisibilización del EZLN en los mismos circuitos turísticos que se han beneficiado de su notoriedad internacional, este trabajo se posiciona en los planteamientos teóricos de Henri Lefebvre y Claude Raffestin. Lefebvre (2013) define el espacio como un producto de las relaciones sociales a lo largo de un proceso histórico: es "un medio de producción, un medio de control y, en consecuencia, de dominación y de poder, pero que escapa parcialmente, en tanto que tal, a los que se sirven de él" (Lefebvre, 2013:86).Considerando que "el poder es un componente en cualquier relación" (Raffestin, 2013:74) y que el Estado es el actor más relevante del grupo primario de organizaciones, la influencia de esta entidad es determinante en la forma en que se ordenan las relaciones sociales del espacio producido, reacondicionándolo según sus propósitos. Así, para analizar las dinámicas turísticas generadas en torno al levantamiento zapatista, será útil identificar los objetivos tras los cuales las instituciones estatales implementan acciones estratégicas, y cómo éstas afectan y se relacionan con los grupos sociales y organizaciones secundarias que comparten el espacio producido. 
La asimetría en las relaciones sociales producidas en un lugar determinado involucra a la sociedad civil, a los visitantes y al Estado (interesado en ejecutar sus objetivos explícitos y encubiertos). Esta asimetría favorece el crecimiento de una estructura en detrimento de otra. El planteamiento de Raffestin sobre las nudosidades, centralidades y marginalidades, en el orden de las relaciones sociales que producen los distintos territorios, ayuda a desentrañar cómo es que los grupos estudiados, desde su posición de centralidad o marginalidad, producen el espacio turístico: la exclusión es una forma con que el Estado dirige y controla las fuerzas sociales (Raffestin, 2013).

Para el caso específico de Los Altos de Chiapas - y su nodo urbano San Cristóbal de las Casas - es ilustrativo el planteamiento de Aguirre Beltrán (1991:15-16) sobre las "regiones de refugio", pues el autor describe los mecanismos "dominicales" por medio de los cuales la élite gobernante ha ejercido dominio en la población indígena a través de la estratificación de dos sociedades marcadamente diferenciadas: la criolla (denominados en esta ciudad como "coletos" o "ladinos")y la indígena. La diferencia étnica ha justificado la discriminación y exclusión sociocultural y espacial en forma dicotómica: mientras el grupo coleto-ladino ocupa el centro de la "ciudad señorial", los distintos grupos indígenas - principalmente, tzotziles y tzeltales (INEGI, 2004) - se ubican en el hinterland de esta ciudad, reflejando la permanencia anacrónica de una lógica colonial.

En este ordenamiento socio-territorial, los indígenas representan la antítesis de la civilización, encarnando tanto al "salvaje que está siempre presente y habita en los confines inmediatos de la comunidad: se encuentra en el bosque cercano, en la montaña" (Bartra, 1992:19), como al ‘bárbaro’ que amenaza al individuo y al orden de la polis con su llegada que, desde lugares muy lejanos, es imaginada "como un apocalipsis" (1992:19).Pero, al mismo tiempo, el indígena que logra incorporarse al espacio urbano lo hace dentro del mecanismo dominical de exclusión y dominación: marginado de los espacios políticos de decisión; dependiente económicamente, reducido "a la condición de un instrumento de uso" (Aguirre, 1991:47); sin acceso a servicios y derechos fundamentales (como la educación formal) y a ciertos espacios centrales (París, 2000; Castellanos, 2001; Cañas, 2016).

Lo anterior enmarca el análisis del fenómeno turístico en cuestión, considerando que "la explicación del consumo de servicios turísticos no se puede separar de las relaciones sociales en las que están enclavados" (Urry, 2002:129; traducción propia). A continuación, antes de presentar los hallazgos del trabajo de campo, se hace una revisión breve de los antecedentes históricos y las discusiones más relevantes que contextualizan el fenómeno turístico surgido en la ciudad de San Cristóbal de las Casas y sus alrededores, a partir del levantamiento zapatista.

\section{CERCO CONTRAINSURGENTE AL APOYO INTERNACIONAL}

El levantamiento armado del EZLN fue la forma radical y organizada de diversos pueblos indígenas de Los Altos de Chiapas y de la Selva Lacandona para luchar contra las estructuras de poder que les han mantenido en condiciones de pobreza extrema. Además delas causas inmediatas - crisis económica, caída del precio del café e ingreso de México 
al $\mathrm{TLCAN}^{2}$ - había razones históricas de explotación finquera y la falta de tierras que se hizo dramática a partir del desconocimiento de los derechos de alrededor de cien mil colonos - principalmente tzeltal, chol y tojolabal - a establecerse en la Selva Lacandona, con un Decreto Presidencial de 1972 (Harvey, 2000).Esto implicó violentos desalojos y desplazamientos que pauperizaron a la población a tal grado que "las comunidades afectadas empezaron entonces a vislumbrar la posibilidad de resistir con las armas en la mano" (De Vos, 2002:365).

Después de que el zapatismo le declarara la guerra al Estado de México, las comunidades simpatizantes se convirtieron en un blanco, al apoyar al movimiento insurgente. Desde un primer momento, el Estado buscó controlar la circulación de personas y la transferencia de ayuda e información, instalando retenes militares en las principales rutas que conectaban a San Cristóbal con sus alrededores, con la explícita violación a los DDHH de la población civil, principalmente indígena. Justificado en su "deber y la facultad para protegerse contra las acciones violentas, y de tomar acciones militares contra grupos armados disidentes" (CIDH, 2016:27), el Estado mexicano llevó a cabo graves abusos, tal como señala el informe "Mexico: Waitingfor Justice in Chiapas" de1994,el cual documenta una serie de ejecuciones extrajudiciales de zapatistas en Ocosingo, San Cristóbal, Las Margaritas y Altamirano.Sin embargo, las miradas del mundo en Chiapas permitieron, según señaló el Subcomandante Marcos, elevar "el costo de la sangre indígena" (Le Bot, 1997:185) durante la respuesta contrainsurgente que,según cifras oficiales, dejó 145 muertos, aunque según la Diócesis de Chiapas fueron más de quinientos (Physicians For Human Rights y HRW, 1994; Pitts, 1996).

Conscientes de la importancia estratégica del control de la información,durante los Diálogos de Paz y la Convención Nacional Democrática - llevados a cabo en San Cristóbal de las Casas en 1994-, el EZLN eligió a los medios de comunicación independientes para hacer llegar sus comunicados, mientras vetó a Televisa y Televisión Azteca - duopolio de los medios informativos mexicanos - por su cuestionado comportamiento ético (Gil Olmos, 2014; Volpi, 2004; De la Grange y Rico, 2005). Al mismo tiempo, fue articulando una red de solidaridad con ONG nacionales, sudamericanas, estadounidenses y canadienses (Hernández, 2017).Con la masificación de internet, las redes de apoyo del EZLN lograron sortear el cerco mediático y difundir globalmente sus ideas e imágenes, tal como ocurrió con la creación de la página web ¡Ya Basta! (www. ezln.org), por el profesor de la Universidad de California, Justin Paulson, "a través de la cual se diseminó por todo el mundo la imagen y el discurso de los zapatistas, en especial de Marcos" (Gil, 2014:138-139). Estos operativos le permitieron al EZLN legitimarse y captar miles de simpatizantes en todo el mundo, construyendo vínculos de cooperación,

2 Además de las fuertes caídas del precio del café que, a partir de 1989, afectaron a los pequeños productores del estado (González Casanova y Cadena Roa, 1994), en 1992 se reformó el artículo 27 constitucional para clausurar el derecho de los desposeídos a la tierra y eliminar las trabas que impedían que la propiedad ejidal fuera parcelizada y privatizada, permitiendo su incorporación al mercado mundial. Uno de los logros más importantes alcanzados por la Revolución Mexicana - que aseguraba y protegía la dotación de tierras ejidales a pueblos y comunidades - era desmantelado para allanar el camino a la firma del Tratado de Libre Comercio de América del Norte (TLCAN), el cual sometería a los agricultores nacionales a la demanda de los mercados de Estados Unidos y Canadá (Le Bot, 1997; Legorreta Díaz, 1998;Leyva Solano y Ascencio Franco, 2002). 
al mismo tiempo que la respuesta del gobierno mexicano era cuestionada ante la opinión pública (Leyva Solano, 2009).

En cuanto al control territorial, a fines de 1994 el EZLN creó los Municipios Autónomos Rebeldes Zapatistas (MAREZ) como forma de reconfigurar un ordenamiento político social propio, con delimitaciones diferentes a los municipios oficiales, en alrededor de 250,000 hectáreas recuperadas inicialmente de manos de grandes propietarios de los Altos y del norte de Chiapas (Gutiérrez Luna, 2012). Reivindicando su derecho a la autodeterminación, incluido en la Constitución Política de México ${ }^{3} y$ en instrumentos jurídicos internacionales como el Convenio 169 de la OIT, las comunidades zapatistas buscaron proponer, de esta forma, una lógica contra-hegemónica de producir el espacio social en las tierras recuperadas (López Monjardiny Rebolledo Millán, 1999; Mattiace et al., 2002). Esto generó la respuesta del Estado mediante una serie de medidas políticas y administrativas, como la reestructuración municipal (Leyva Solano y Burguete, 2007), y militares (Marín, 1998; José, 2017; Ramos, 2017) para "destruir la voluntad de combatir del EZLN" (SEDENA, 1994:1). La militarización de la zona, agudizada con la creación de fuerzas paramilitares, propició el desplazamiento de aproximadamente 22,000 campesinos que tuvieron que refugiarse en las montañas de Los Altos (Rebón, 2001). El hecho de mayor gravedad padecido por los desplazados se llevó a cabo a fines de 1997 en Acteal, municipio de Chenalhó, donde fueron masacradas 45 personas por grupos paramilitares (Frayba, 1998).

Estas medidas contrainsurgentes desencadenaron una de las peores crisis humanitarias en la zona que, a su vez, incrementó la llegada de caravanas de ayuda a la población afectada y de observadores para registrar y denunciar las violaciones a los derechos humanos cometidas por el ejército y por paramilitares (Frayba, 2001; Castro Soto, 2000; HRW, 1997; SIPAZ, 2006). El Estado reaccionó estableciendo, a partir de 1998, una serie de restricciones a los observadores de DDHH por medio de una circular del Instituto Nacional de Migración (INM) (SEDENA, 1994; INM, 1998; Earle y Simonelli, 2005; Amnistía Internacional, 1999). Esto obligó a elaborar estrategias de ingreso y medidas de protección para que los observadores pudieran realizar su trabajo sin ser deportados, lo que implicaba ingresar como turistas y efectuar discretamente sus labores en forma clandestina, mimetizándose entre los turistas tradicionales percibidos como despolitizados (Castro Soto, 2000; Scherer Ibarra y López, 2000; Frayba, 2017; Ascencio, 2017).

Durante el trabajo de campo realizado, se pudo constatar la vigencia de esta persecución y la presión que se ejerce sobre la expresión del apoyo al movimiento zapatista. En 2016, se pudo atestiguar que, ante una exhibición artística de simpatizantes zapatistas - en su mayoría extranjeros - frente a la Catedral de San Cristóbal de las Casas, los policías hicieron meticulosos registros fotográficos y audiovisuales, tal como se puede apreciar en la Figura 3. En 2017, durante una Caravana de observación hacia el pueblo de Cruztón, los vehículos fueron seguidos y grabados por algunos taxistas hasta la salida de San Cristóbal de las Casas.

3 "El pueblo tiene en todo tiempo el inalienable derecho de alterar o modificar la forma de su gobierno" (CPEUM, 1917:artículo 39). 


\section{Figura 3 \\ EXPOSICIÓN PRO-ZAPATISTA EN ZÓCALO DE SAN CRISTÓBAL DE LAS CASAS}

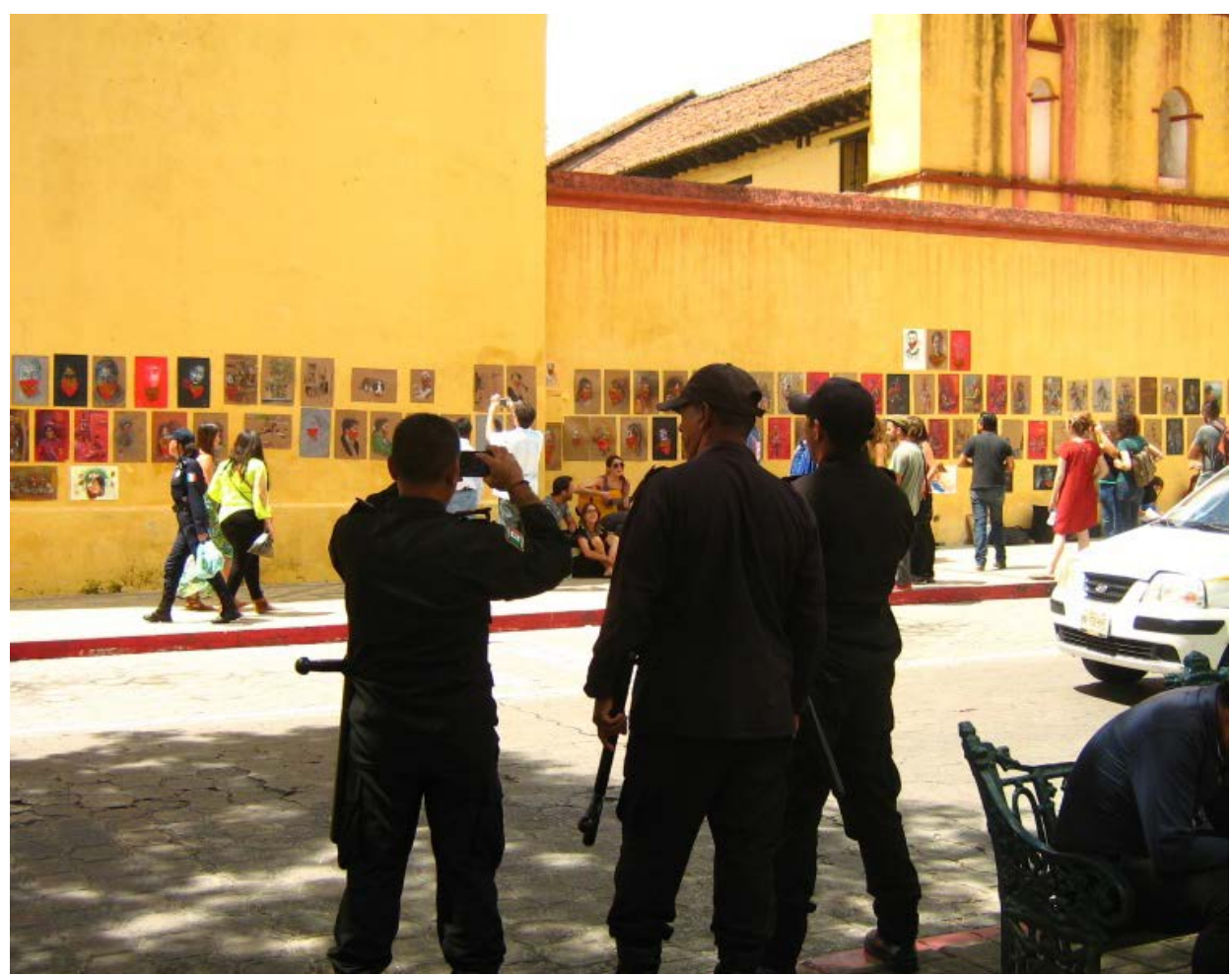

Fuente: fotografía de Patricia Viera-Bravo, 2016.

Cabe señalar que, a partir del conflicto zapatista, también se acrecentó la llegada de turistas que buscaban internarse en comunidades zapatistas a través de agencias o programas como los Reality Tours organizados por la ONG estadounidense Global Exchange. Los turistas que participaban en estos Reality Tours cumplían el doble propósito de aproximarse a la experiencia revolucionaria y "actuar como ojos y oídos para el resto del mundo" (Janzen et al., 2015:153; traducción propia), lo cual provocó que, en 1999, el gobierno mexicano le denegara la autorización de ingreso al director de su programa para México (Babb, 2011; Global Exchange, 1999; Castro Soto, 2000; Beltrán del Río, 1999). Estas experiencias fueron volviendo más herméticos a los observadores y simpatizantes del zapatismo con respecto a manifestar públicamente el verdadero interés y objetivo de su estancia en la zona. Por lo tanto, aunque su presencia esté relacionada directamente con el EZLN, estos visitantes no podrían considerarse como generadores de una demanda turística, en los circuitos tradicionales, específicamente relacionada con este movimiento. 


\section{LO VISIBILIZADO POR EL TURISMO TRADICIONAL EN SAN CRISTÓ- BAL DE LAS CASAS}

La conectividad estratégica de San Cristóbal de las Casas con los pueblos indígenas aledaños ha posicionado a esta ciudad como el núcleo central de la región de Los Altos. La diversidad étnica que converge desde los márgenes a la ciudad, se convirtió en uno de sus mayores atractivos turísticos, aunque esta valoración ha sido históricamente contradictoria. A mediados del siglo pasado, De la Peña (1951) describe a la población indígena que confluye desde los márgenes de la ciudad de la siguiente manera: uno de los “muchos atractivos de primerísima importancia [...] único en su género y no por ello menos doloroso y vergonzoso para México: el de los indios que bajan a esta ciudad a su tianguis diario" (De la Peña, 1951:1117).

En la misma época, la llegada de la carretera Panamericana sacó a San Cristóbal de las Casas del aislamiento, permitiendo el desarrollo del turismo (Harvey, 2000; Garza Tovar y Sánchez Crispín, 2015); entre los nuevos visitantes comenzaron a arribar investigadores y estudiosos interesados en la cultura y los pueblos mayas. El Centro de Estudios Científicos Na Bolom, creado en 1950 por el arqueólogo danés Franz Blom y la periodista suiza Gertrude Duby, les brindó un espacio donde llegar, convirtiéndose en la puerta de entrada para la realización de innumerables estudios antropológicos que difundieron la cultura maya por todo el mundo - principalmente de los lacandones - (González, 2016). Como espacio de aproximación a los pueblos indígenas de la región, $\mathrm{Na}$ Bolom fue pionero en contribuir al desarrollo de lo que Van den Berghe y Keyes (1984) denominaron turismo étnico o "etnoturismo".

En los años setenta se registraron algunas mejoras en la ciudad (Babb, 2011; Garza Tovar, 2009; Secretaría de Educación y Cultura, 1984), aunque persistió el problema de la"deficiencia de la infraestructura turística de apoyo y complementaria [y una] falta de atractivos" (Comité Promotor del Desarrollo Socioeconómico del Estado, 1979:s/p). Tras la aspiración de convertir a San Cristóbal de las Casas en un destino turístico internacional, en la década siguiente se hicieron esfuerzos gubernamentales por mejorar sus condiciones: en 1986,se estableció la Zona de Monumentos Históricos alrededor del zócalo de la ciudad, con más de quinientos inmuebles coloniales, y se lanzó su candidatura para ser incorporada como Patrimonio de la Humanidad de la UNESCO, aunque a la fecha no ha habido resultados; se incorporó a la ciudad en diversos programas con fondos y recursos especiales, como el programa regional Mundo Maya, en 1988, y el Programa Fondo Mixto Ciudades Coloniales, en 1989 (Garza Tovar, 2009). Estas iniciativas se reflejaron en un leve aumento en la cantidad de turistas en la ciudad, pero sólo en proporción a la mejora de infraestructura, expresada en la cantidad de alojamientos disponibles.

Pero tal como se observa en la Figura 4, sólo a partir de 1994, con el levantamiento armado zapatista, las cifras turísticas mostraron un notorio despegue. Por sus características de ciudad núcleo de Los Altos de Chiapas, San Cristóbal de las Casas se convirtió rápidamente en el centro logístico de los distintos flujos de personas que llegaron a la zona para acercarse al conflicto; aparte de los contingentes militares, los turistas tradicionales cedieron lugar a oleadas sin precedentes de periodistas de todo el mundo que, según cifras extraoficiales, llegaron a ser más de mil durante las primeras semanas (Gil Olmos, 2014; González, 
2016); además, comenzaron a arribar observadores de DDHH, funcionarios y autoridades de gobierno y algunos turistas que, pese a los riesgos, intentaron acercarse al fenómeno.

\section{Figura 4 \\ EVOLUCIÓN DEL NÚMERO DE TURISTAS Y ALOJAMIENTOS EN SAN CRISTÓBAL DE LAS CASAS}

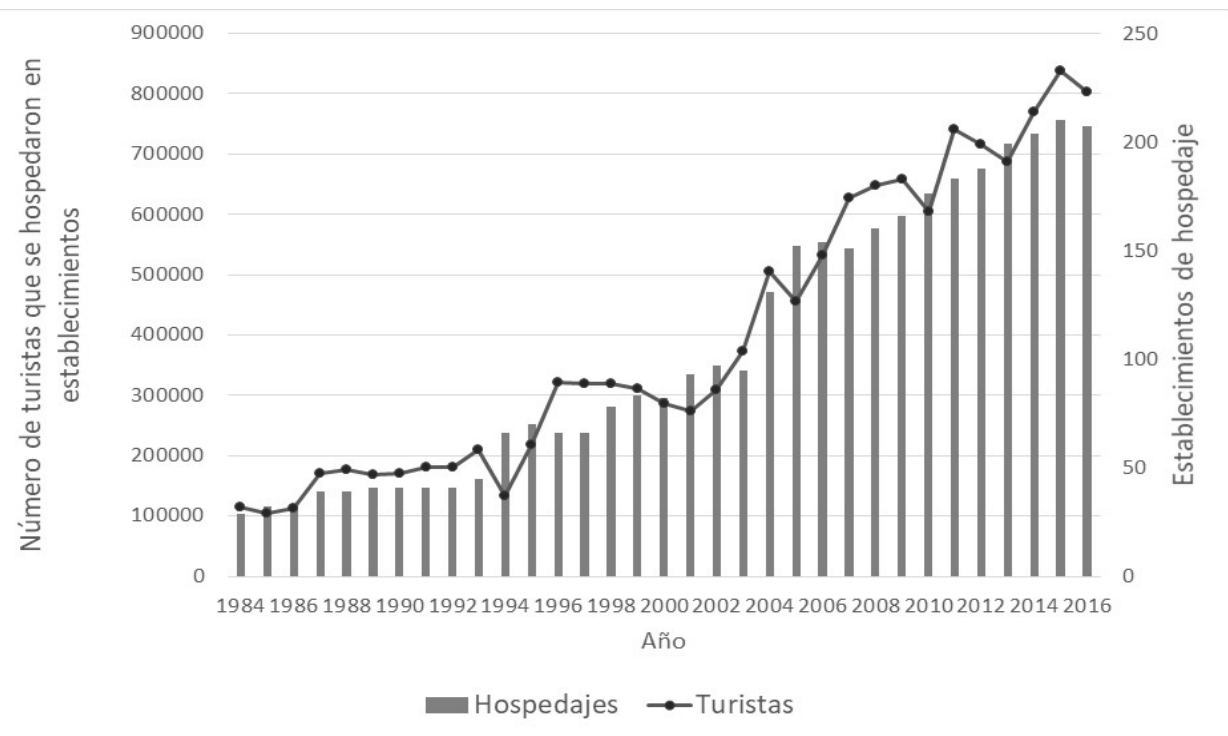

Fuente: elaboración propia con base en datos del INEGI (1984-2017).

No obstante que la llegada de turistas tradicionales se desaceleró en 1994, se reportó una alta demanda de servicios turísticos de hospedaje formales y no formales por parte de los nuevos visitantes vinculados al conflicto zapatista, no considerados como turistas, aunque sí en sus formas de consumo. A partir de entonces, la dinámica de San Cristóbal de las Casas se transformó, tal como lo describen los testimonios de la época: "los autos en renta se terminaron y sobre todo los jeeps, que anteriormente exclusivamente se destinaban a los turistas. Los hoteles se saturaron, los bares se atiborraron todas las noches y la población local [...] manifestaron su rechazo a quienes llamaban 'extranjeros' por vivir fuera de la región" (Gil Olmos, 2014:54).

En este punto comenzó a conformarse un tercer grupo social que rompió y reconfiguró la dinámica polarizada que imperaba en la sociedad de San Cristóbal de las Casas y de los Altos: un heterogéneo grupo de visitantes - muchos establecidos por largas temporadas $\mathrm{o}$ indefinidamente $-\mathrm{y}$ turistas, tanto extranjeros como mexicanos. Al mismo tiempo que la sociedad local empezó a sentirse abrumada e invadida por el exponencial aumento de visitantes, muchos empresarios locales lo fueron capitalizando para abrir nuevos sitios de hospedaje y ampliar la oferta de servicios turísticos (Adriana, 2017; Ulises, 2016). 
El repliegue zapatista de Los Altos y del norte de Chiapas hacia las montañas, tras la contraofensiva del ejército mexicano, de cierta manera garantizó la estabilización y dinamización de la actividad económica de la ciudad (Morquecho, 2016; Ascencio Cedillo et $a l ., 2011)$. En las cifras de la actividad turística se observa que, después del despegue, hubo un breve estancamiento para luego dar nuevamente un salto cuantitativo importante en 2003, tras el nombramiento de San Cristóbal de las Casas dentro del listado de Pueblos Mágicos de México ${ }^{4}$. La evidente mejora en la infraestructura turística y los espacios urbanos, ha servido como plataforma para el despegue de esta actividad que, con el paso del tiempo, ha ido recibiendo mayor cantidad de turistas tradicionales: "de lo que vimos en los primeros años ya no queda nada de la ciudad" (Morquecho, 2016:s/p).

En los primeros años que siguieron al levantamiento del EZLN, se observó la aparición de un tipo de turistas interesados en aproximarse al fenómeno zapatista; se trató sobre todo de turistas extranjeros deseosos de experimentar la emoción de visitar alguno de los lugares relevantes del conflicto armado sui géneris, que además presentaba características particulares: el sujeto indígena había logrado posicionar su lucha por la autodeterminación como una demanda justa y legítima, superando la histórica estigmatización con que los habían marginado en sus propios territorios originarios. Por otro lado, su vocero, el Subcomandante Marcos, captaba diversos apoyos entre la militancia de izquierda, a partir de una figura que permitía evocar las revoluciones pasadas y romantizar la actual.

Existe literatura que permite identificar a los visitantes que se acercaban a la zona del conflicto zapatista como "turistas de guerra" (Pitts, 1996) o como "turistas oscuros" (Foley y Lennon, 1996; Van Broeck y López, 2018), en alusión a la búsqueda de espacios y experiencias disonantes. Para atender esta demanda, desde principios de 1994, la agencia de viajes Los Anfitriones comenzó a ofrecer las primeras excursiones hacia comunidades de base zapatista. Desde entonces, los viajes ofrecidos por agencias y ONG para llevar turistas o activistas a las zonas zapatistas se popularizaron con el nombre de zapatours (Babb, 2011; Gil Olmos, 2014; Coronado, 2008; Alexander, 2016; Empresario, 2016; Domínguez, 2017; Guía 3, 2017; Gutiérrez, 2017). No obstante, según relatos de agentes turísticos de la época, muchas de estas excursiones fueron simulaciones de encuentros con zapatistas o, de ser real, la aproximación se realizaba en forma superficial (Empresario, 2016); llegaban para "ver cómo eran, de qué color eran y se iban" (Morquecho, 2016:s/p), sólo asistían para "«rasguñar» la realidad sin apreciar su complejidad" (Hiernaux, 2006:403). En una línea más politizada, Florence Babb denomina a estos turistas como "turistas revolucionarios", los cuales estarían "estimulados por la revolución y el levantamiento [...] como resultado del interés y la atención suplementaria que va de la mano con la apertura o reapertura del turismo en áreas donde ha habido disturbios sociales" (Babb, 2011:117; traducción propia).Sería una forma romántica o nostálgica de acercarse a los intentos de cambio social o de construcción de utopías comunitarias, buscando la emoción de ser testigos del surgimiento de nuevas propuestas políticas como el zapatismo civil (Leyva Solano, 2009; Le Bot, 1997; Alexander, 2016).

4 Programa gubernamental para el financiamiento y fomento turístico de algunas localidades mexicanas que, a juicio del gobierno federal, merecen ser apoyadas por su alto valor cultural, patrimonial y natural. Una visión crítica de este nombramiento se puede revisar en Cañas (2016). 
A pesar de que San Cristóbal de las Casas y Chiapas han logrado reconocimiento internacional gracias al movimiento zapatista, éste no se ha insertado como atractivo relevante en la oferta turística tradicional y, de acuerdo con diversos testimonios recabados, el flujo de visitantes motivados por el EZLN ha decrecido considerablemente. Su presencia en los principales circuitos turísticos se limita a algunas imágenes en postales y afiches y a muñequitos con pasamontañas (principalmente, de la Comandanta Ramona y el Subcomandante Marcos) que se pueden comprar en el mercado de Santo Domingo o en pequeñas tiendas en el extremo oriental del andador turístico de Real Guadalupe (Figuras 2, 5 y 6).

Figura 5

TIENDA PRO-ZAPATISTA EN EL ANDADOR DE GUADALUPE

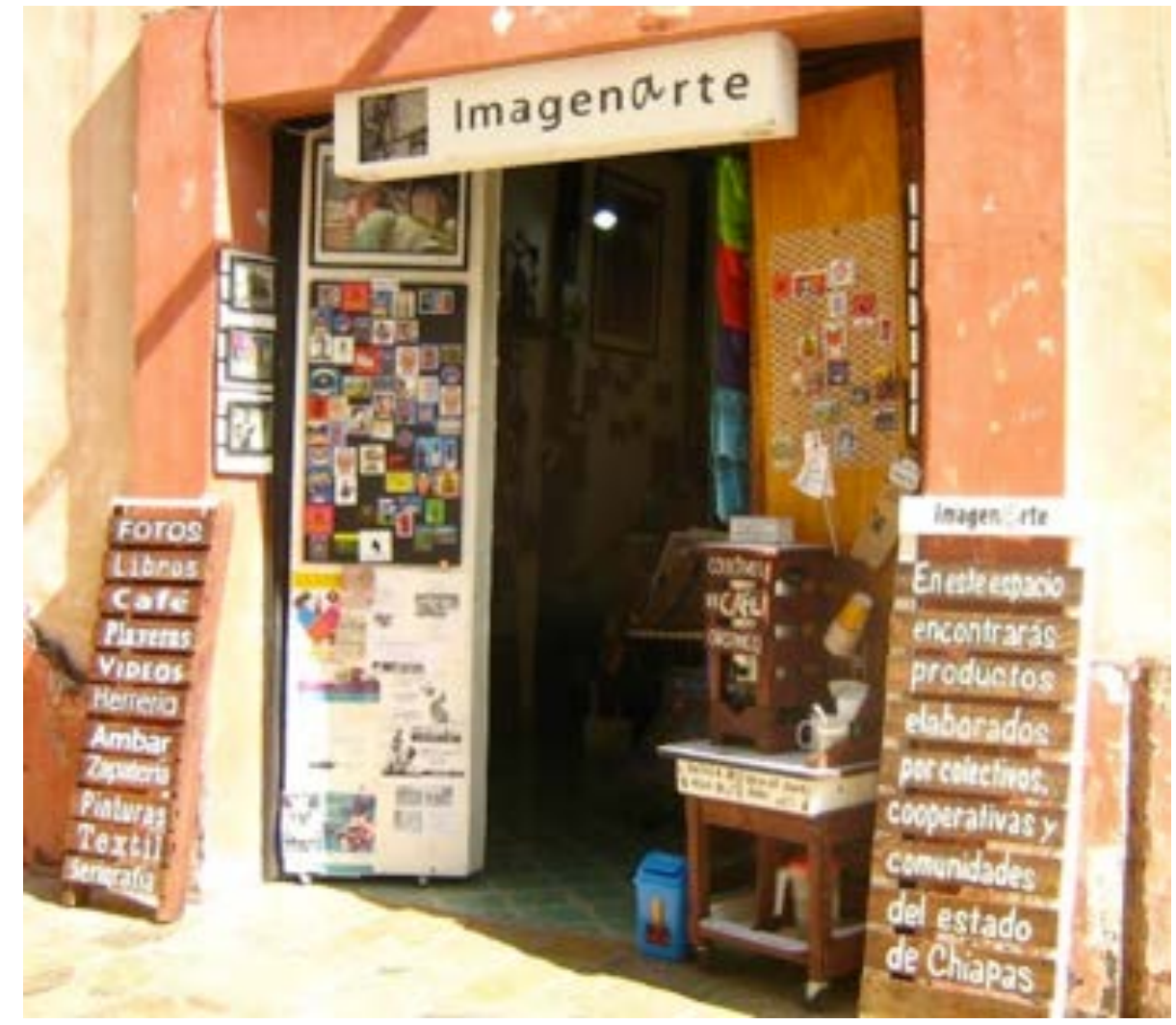

Fuente: fotografía de Patricia Viera-Bravo, 2017.

El papel del gobierno en el direccionamiento del desarrollo turístico en la región del conflicto se evidencia en la creación de la Secretaría de Turismo del Estado de Chiapas, en marzo de 1994, la cual se ha esmerado en construir una imagen pacífica del estado, a fin de dar seguridad al turismo nacional e internacional (Morales, 2016). Recentrando el interés turístico de San Cristóbal de las Casas en su pasado maya y colonial, se ha continuado pro- 
yectando la imagen del sujeto indígena contemporáneo como “objeto de exhibición” (Cañas, 2016:16) en espacios específicos y delimitados. Su despolitización podría verse favorecida por las supuestas sanciones que recibirían los guías turísticos que hicieran referencias a los procesos políticos recientes dentro de los recorridos tradicionales. Según fuentes entrevistadas, podrían sufrir la revocación de sus credenciales de acreditación como guías turísticos, aunque SECTUR-Chiapas niega esta información (Guía 1, 2017; Guía 2, 2017; Guía 3, 2017; Morales, 2017).Entonces, se puede asumir que los intereses políticos y económicos estatales han influido en la producción del espacio social de la ciudad, restringiendo en sus principales circuitos turísticos la presencia de elementos que aludan al zapatismo actual y sus contenidos simbólicos, como representantes de una crítica al orden hegemónico.

\section{Figura 6 SOUVENIRS EN TIENDA PRO-ZAPATISTA}

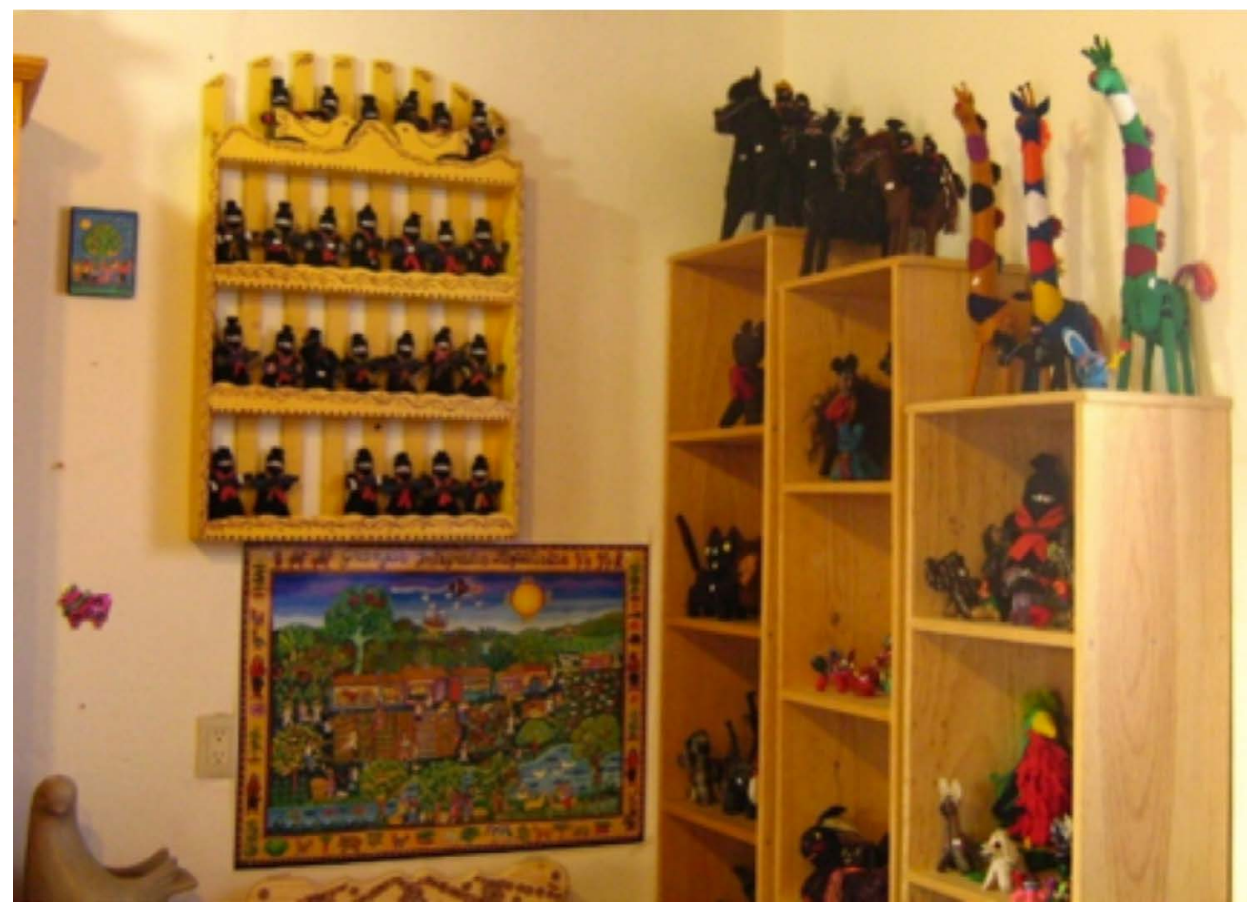

Fuente: fotografía de Patricia Viera-Bravo, 2017.

\section{NUEVAS CENTRALIDADES ZAPATISTAS Y APOYO EXTERNO}

Desde el levantamiento zapatista, las relaciones sociales en San Cristóbal de las Casas se han reconfigurado con la incorporación de nuevos grupos sociales y de nuevas centralidades que han emergido en los territorios zapatistas. Muchos de los grupos de extranjeros y mexicanos de otros estados que arribaron a San Cristóbal de las Casas lo 
hicieron motivados por la oportunidad que parecía abrirse de presenciar o experimentar formas alternativas de organización social y política protagonizada por las comunidades indígenas zapatistas (Ascencio Cedillo et al., 2011). Sin embargo, estas comunidades ya contaban con décadas de experiencia en procesos organizativos de carácter comunitario (Ruíz, 2017), constituidos en torno a varios ejes: "ser católico de la Teoría de la Liberación/ maoísta/ miembro de la U. de U. [Unión de Uniones] / hablante de lengua indígena/ habitante de Las Cañadas" (Leyva Solano y Ascencio Franco, 2002:171).

En el nuevo ordenamiento territorial propuesto por el zapatismo, los MAREZ se constituyen en la instancia local de la organización social autónoma integrada por las bases de apoyo del EZLN y por campesinos e indígenas pertenecientes a organizaciones aliadas (González, 2017). En el camino fueron apareciendo nuevas necesidades de constituir estructuras más agregadas como las Asociaciones de Municipios Autónomos, creadas en 1997, o las JBG, creadas en 2003 para articular un conjunto de comunidades y municipios distribuidos alrededor de cada uno de los cinco Caracoles (EZLN, 2003), los antiguos Aguascalientes construidos como"espacios para el encuentro y el diálogo entre el EZLN y la sociedad civil nacional e internacional” (Martínez, 2006:231). Cada Caracol pasó a ser el "espacio que cobija la unidad administrativa de gobierno, superior a los municipios y reuniendo también los centros de salud y las escuelas secundarias" (Houtart, 2013:2) donde se ejerce el autogobierno y se toman las decisiones supra comunitarias fundamentadas en los principios de reciprocidad, soberanía alimentaria, y con prácticas de democracia directa y participativa (JBG, 2017; Martínez, 2006; Gutiérrez Luna, 2012).

Por el carácter contra-hegemónico de esta propuesta, las comunidades debieron enfrentar - aparte de las acciones militares y paramilitares - los "ataques económicos" del Estado que utilizó programas sociales y de desarrollo como arma de contrainsurgencia (SEDENA, 1994; Leyva Solano y Burguete, 2007), dividiendo a las comunidades y cooptando a los miembros de la organización rebelde (Susana, 2017). Por lo mismo, se estableció la regla de no recibir ayuda financiera del Estado (al que denominan "mal gobierno") e incluso, de revisar y condicionar cualquier ayuda externa (JBG, 2017). Lo que ellos mismos han descrito en diversos eventos y comunicados, se ha podido corroborar durante la primera versión de la Escuelita Zapatista, en agosto de 2013. Desde las JBG se organizan las principales áreas de trabajo: "salud, educación, comercio, tránsito, administración, agraria, justicia, derechos humanos y campamentistas" (EZLN, 2013:9). Las formas de financiar las funciones y actividades comunitarias se basan en diferentes trabajos colectivos como crianza de ganado, cultivo de milpa, frijolares, cafetales, platanares, cañales o tiendas de abarrotes, con el objetivo de mantener fondos económicos (EZLN, 2013). Con el escaso excedente producido, una comunidad mantiene a sus promotores locales de salud y educación, mientras cada familia debe asegurar su propio abastecimiento alimentario manteniendo huertas orgánicas en sus terrenos domésticos, con la posibilidad opcional de criar aves de corral o ganado.

Las nuevas centralidades articulan estas relaciones sociales y de producción independientes de los núcleos económicos hegemónicos que los han marginado históricamente, los mismos que a partir de 1994 se han beneficiado del aumento del turismo atraído por el levantamiento armado. Entonces, la escasa presencia del movimiento zapatista en los principales circuitos turísticos de San Cristóbal de las Casas y sus alrededores tendría 
que explicarse además por factores internos: la apuesta política por construir circuitos alternativos de intercambio, dentro de los criterios del comercio justo y reciprocidad, no les permitiría ser competitivos con sus productos (principalmente, café orgánico, libros y artesanías) en los circuitos turísticos tradicionales de la ciudad 5 . De esta forma, el acceso de los turistas a estos productos es posible sólo en los márgenes del centro turístico, llegando por previo conocimiento o recomendación dentro de círculos de confianza acotados, generalmente de perfil politizado y militante.

Por otra parte, al intentar desmarcarse de las estructuras de asistencialismo y clientelismo del Estado mexicano para sostener la autonomía, los zapatistas han buscado vincularse con redes de apoyo externas, tanto nacionales como internacionales, mediante canales de intercambio y comunicación alternativos. Considerando el estado de extremo rezago y vulnerabilidad en que han sobrevivido estas comunidades durante décadas, ha sido indispensable la ayuda solidaria externa para mejorar las condiciones materiales y ampliar el espectro de necesidades atendidas, más allá de las básicas. Sin embargo, surge la paradoja que señaló Aguirre Beltrán: "la autonomía, en condiciones de marginalidad, no favorece al indio, lo expone a intereses extraños de toda índole. La amenaza real para la población indígena está en detener su transformación, en mantenerlos en la marginalidad y congelar las identidades" (Arrieta, 1999:203).

En este sentido, tras el objetivo de captar simpatizantes foráneos, la cúpula del EZLN ha dedicado importantes esfuerzos en construir una identidad de carácter transnacional que pudiera aglutinara sujetos y organizaciones en torno a un enemigo común: el capitalismo neoliberal. Con la habilidad para articular diversas particularidades geográficas, idiomáticas, culturales, religiosas y de formación política, este movimiento consiguió superar el aislamiento histórico y los cercos contrainsurgentes para "traducir su lucha en términos reconocibles para otros lugares del mundo y logró un efecto universalizante que iluminó la posibilidad de una lucha global" (Rovira, 2009:14). De esta manera, las nuevas centralidades zapatistas se han ido relacionando con organizaciones y sectores sociales que, desde otras marginalidades, levantan sus distintas luchas contra-hegemónicas, a partir de “acciones políticas, desde las de carácter simbólico y de difusión de información, hasta la garantía de presencia internacional en las comunidades, fiestas, encuentros, visitas, o la búsqueda de dinero para sostener al municipio" (2009:172). Un ejemplo son las relaciones de hermanamiento construidas entre los MAREZ y "entidades territoriales descentralizadas [con] marcado activismo solidario de grupos libertarios e igualitaristas provenientes especialmente de ciertas regiones europeas (País Vasco, Cataluña, algunas ciudades y regiones de Italia, Francia, Alemania o Grecia)" (Baronnet, 2009:274-275)6.

5 Tal como se pudo constatar en el trabajo de campo, si bien existe un interés importante por conocer más del EZLN, dentro de los circuitos turísticos comerciales existen contados espacios donde encontrar información, como el Foro cultural independiente Kinoki que permanentemente exhibe documentales zapatistas y ofrece espacios para foros de denuncia y cine-debate organizados, principalmente, por el Centro de Derechos Humanos Fray Bartolomé de las Casas y por la ONG Otros Mundos Chiapas.

6 Rovira detalla varias de estas experiencias de intercambio que se realizan desde 1998: hermanamientos entre los MAREZ San Andrés Sacanchem de los Pobres, San Juan de la Libertad, Tierra y Libertad, Ricardo Flores Magón, Lucio Cabañas y El Trabajo, con los municipios de Empoli, Cinisello Balsamo y Lastra Signa, la provincia de Lucca y la ciudad de Livizzano, de Italia, además del sindicato español Confederación General del Trabajo y de la Sociedad civil catalana La Garriga (Rovira, 2009).

Cuadernos de Turismo, 47, (2021), 277-301 
En este punto, Yves Le Bot (1997) simplificó el intercambio entre el zapatismo y el apoyo internacional en los siguientes términos: el primero ofrece "sentido a cambio de alimento y un escudo humano" (1997:93). La cúpula del EZLN ha tendido a quedar atrapada en la función de generador de contenidos a escala transnacional y, al mismo tiempo, en la exigencia de mantener "una supuesta «alteridad auténtica» situada fuera de las formas generalizadoras de la globalización" (Harvey, 2003:94). Esto remite a una advertencia premonitoria de Le Bot sobre los posibles resultados dicotómicos de esta propuesta: “el peligro del aislamiento y del repliegue, de la asfixia comunitarista [y, por otro lado,] el peligro de un alejamiento, de una desconexión respecto de las realidades chiapanecas, de un lanzamiento a la órbita «intergaláctica»" (Le Bot, 1997:95).

Al filtrar lo que se muestra hacia el exterior, la cúpula del EZLN busca su protección y la de las bases de apoyo frente a las acciones contrainsurgentes y paramilitares que las asedian, pero, al mismo tiempo, busca responder, dentro de lo posible, a las expectativas de los apoyos solidarios externos. En este proceso, los problemas cotidianos y concretos que enfrentan las bases de apoyo no han logrado un espacio significativo donde ser denunciados y difundidos, tal como se ha podido observar en distintos eventos masivos organizados por el EZLN y sus simpatizantes, a excepción de la Escuelita Zapatista de 20137. Los diversos conflictos territoriales, aún vigentes en Las Cañadas de Chiapas, quedan absorbidos por la retórica antineoliberal que se refiere al sistema hegemónico con la imagen mítica de una Hidra-Capitalista, diluyendo en ella los nombres y coordenadas reales de los enemigos concretos que materializan el despojo y los crímenes en contextos locales. De esta forma, la invisibilización de las problemáticas actuales de las comunidades zapatistas se refuerza en la escala local del movimiento, aunque esto ocurre como consecuencia del mismo cerco mediático y militar que los ha atrapado en una relación de dependencia con la solidaridad nacional e internacional, frente a quienes asumen un papel de "protegidos" y de "suplemento del alma" (Le Bot, 1997:93).

Al ocultar las complejas coordenadas de su identidad específica —origen geográfico/ étnico/ cultural, adscripción religiosa/ política, etc. - todas las particularidades del mundo se pueden identificar en su lucha, articuladas en torno al capitalismo neoliberal como enemigo omnipresente. El pasamontañas permite graficar estas dos caras de la invisibilización: usado para mantener el anonimato frente a posibles represalias de las fuerzas contrainsurgentes, a su vez esconde el rostro, el origen, la geografía y la historia particular de cada luchador y luchadora. Las bases de apoyo corren el riesgo de sacrificar su visibilidad por la necesidad de convertirse en el espejo en que sujetos de otras latitudes se puedan ver representados desde sus propias luchas, en la línea del incluyente mensaje de uno de los primeros comunicados zapatistas: "Marcos es gay en San Francisco, negro en

7 En agosto de 2013, en el marco de la primera Escuelita Zapatista, se tuvo la oportunidad de habitar durante casi una semana en el cotidiano de una familia zapatista en las mismas condiciones de habitabilidad y hostigamiento por parte de militares y de los habitantes no-zapatistas del mismo pueblo. Se pudo conversar largamente sobre la historia y la visión de esa familia con respecto a la pertenencia al zapatismo, los cambios concretos para sus vidas, en términos materiales y de conciencia social y política. Por otro lado, durante los seminarios semanales que se realizan en forma abierta en el CIDECI de San Cristóbal de las Casas, se pudo observar un recuento acucioso de los principales hechos ocurridos en comunidades de bases de apoyo zapatista. Sin embargo, la difusión de la información está acotada a la asistencia de alrededor de 50 personas, muchas de las cuales son visitantes o turistas eventuales. 
Sudáfrica, asiático en Europa, chicano en San Isidro, anarquista en España, palestino en Israel, indígena en las calles de San Cristóbal [...]" (EZLN, 1994b:s/p) y un largo etcétera.

El riesgo de invisibilización interna requiere realizar una revisión de la dirección de los esfuerzos para romper los cercos impuestos externamente, como lo hizo la Escuelita Zapatista de 2013 que ofreció una oportunidad significativa de acercamiento y experimentación de la realidad local de las comunidades en forma directa, sin interlocutores ni intermediarios. Deben continuar fortaleciéndose los procesos de aprendizaje desde ambas partes para trascender las idealizaciones y las visiones esencialistas atribuidas a una diversidad de sujetos categorizados como indígenas, que derivan en paternalismos y exotizaciones. Que el pasamontañas no se convierta en la prisión de la escala local donde habitan las bases de apoyo, imprescindible para no diluirse en las dimensiones abstractas y universales de "un mundo donde quepan muchos mundos".

\section{REFLEXIONES FINALES}

Al catapultar a Chiapas al centro de las noticias en el escenario mundial, el levantamiento zapatista se convirtió, sin buscarlo, en un catalizador del despegue de una industria turística que se encontraba en un lento proceso de desarrollo. Varios estudios señalan extrañeza frente al hecho de que el fenómeno zapatista no se haya convertido en un soporte de la oferta turística. Se le atribuye a este fenómeno una supuesta incapacidad para visibilizarse en circuitos locales de mayor flujo, visto como una pérdida de oportunidad para posicionar la imagen del movimiento y, con ello, mantener la vigencia de sus demandas y de su propuesta política. Sin embargo, poco se ha ahondado en el rol del Estado y de sus políticas contrainsurgentes en esta invisibilización, además de las consecuencias directas e indirectas en la construcción de un proyecto político de naturaleza autonómica.

Por esto, en este artículo se proponen determinados factores para analizar cómo han contribuido las acciones contrainsurgentes del Estado en nulificar la presencia del EZLN dentro de las dinámicas del turismo local y regional, desde una perspectiva de las relaciones sociales, como productoras de centralidades en los espacios turísticos de San Cristóbal de las Casas y sus alrededores. Vamos más allá de plantear que la ausencia de la imagen del EZLN en los principales medios de comunicación y centros urbanos de la región se debe a un repliegue de fuerzas para concentrarlas en la construcción de autonomía. De acuerdo con lo observado en terreno, podemos plantear que, más que una incapacidad del EZLN para mantenerse vigente en estos circuitos $-\mathrm{y}$ captar beneficios económicos de su notoriedad mundial-, lo que ha operado es un proceso de invisibilización intencional por parte del Estado mexicano, como parte de su estrategia de contrainsurgencia. La implementación de estas acciones expresa, al mismo tiempo, la falta de voluntad de los gobiernos mexicanos para establecer un diálogo real y cumplir los compromisos acordados en las distintas instancias de negociación. Sin embargo, con la nueva administración del presidente de México, Andrés Manuel López Obrador, parecieran haberse revertido los roles en la búsqueda de diálogo, pero como es un periodo que se encuentra fuera del alcance de este artículo, esta línea deberá ser abordada en nuevas investigaciones.

El cerco militar y comunicacional con que el Estado ha intentado recuperar el territorio controlado por el EZLN, produce acciones de resistencia que buscan sortearlo, 
como la vinculación de las comunidades zapatistas con redes de apoyo con distintos lugares del mundo. La regla de no recibir apoyo del "mal gobierno" busca romper vínculos con los mecanismos dominicales de exclusión y subordinación. Retoman el control político en sus territorios; buscan sostener una autonomía económica basada en la soberanía alimentaria y en la producción colectiva; y han elaborado formas de cubrir necesidades fundamentales de educación y salud en sus distintos niveles y bajo sus propios criterios y formas. Las relaciones que producen los espacios sociales dentro de los territorios zapatistas estarían regidas por la lógica del valor de uso, los principios comunitarios y la vinculación y el apoyo con otras organizaciones y propuestas de carácter autónomo y/o contra hegemónico.

Sin embargo, el apoyo externo que necesariamente tiene que actuar para romper el cerco impuesto por el Estado, ha sido criminalizado y sancionado duramente. La persecución sufrida ha silenciado el trabajo de los observadores de DDHH, quienes han debido invisibilizarse en la zona como un mecanismo de protección al desempeño de esta actividad. Por otro lado, se corre el riesgo de generar dependencia con la solidaridad internacional y con un discurso universalista que identifique y convoque a este apoyo, de tal manera que se deba sacrificar la visibilización de las luchas particulares y diversas que se libran en las comunidades de base, desvinculándose de la escala local que le da el soporte real al movimiento.

Que la imagen del EZLN se encuentre atenuada en los principales circuitos turísticos, confinada a la galería de movimientos revolucionarios del pasado de América Latina, no representa el reflejo del declive de un proyecto político; se encuentra vigente y en constante construcción, como demuestra la reciente creación de once nuevos caracoles, anunciada públicamente en agosto de 2019. La implementación de la autonomía es un proceso dinámico que padece un permanente asedio por parte de los actores hegemónicos, por la amenaza que representa su cuestionamiento concreto al orden impuesto; además de liberarse de los lazos históricos de dominación, intentan producir su propio espacio social en torno a los MAREZ y a los Caracoles, como nuevos centros desde donde se distribuye el poder y las decisiones en forma más horizontal, y se experimentan nuevas maneras de organización que adapten las formas tradicionales a los nuevos contextos de despojo capitalista.

En esta línea, por medio de la candidatura a las elecciones presidenciales de 2018de la vocera del Congreso Nacional Indígena (CNI), María de Jesús Patricio Martínez, el EZLN buscó otra plataforma desde la cual dar visibilidad a los pueblos indígenas del país. Se debe evaluar la pertinencia de ocupar las estructuras hegemónicas para difundir y posicionar, nacional e internacionalmente, una propuesta que va justamente en el sentido contrario. Es preciso valorar también el grado de conexión entre el CNI y las luchas locales de comunidades y pueblos originarios que enfrentan cotidianamente el embate feroz de los grandes grupos económicos. Es innegable la contribución del levantamiento zapatista a la visibilización de las luchas de los pueblos indígenas de todo el continente, como nunca antes en la historia, pero, a más de dos décadas de este hito, el escenario de los movimientos sociales ha cambiado enormemente, siendo necesario avanzar en que esta visibilización se amplíe a cada conflicto con sus particularidades geográficas, históricas y culturales. Quizás sea tiempo de revelarlos rostros que hoy continúan luchando, 
más allá de los relatos del esencialismo estratégico y las cargas mesiánicas que éstos ponen en sus hombros y que los pueden llegar a aislar de otros procesos que se están desarrollando en el resto del país y del continente.

\section{BIBLIOGRAFÍA}

AGUIRRE BELTRÁN, G. (1991): Regiones de refugio. El desarrollo de la comunidad y el proceso dominical en mestizoamérica. Ciudad de México, Fondo de Cultura Económica.

AMNISTÍA INTERNACIONAL (1999): México. Bajo la sombra de la impunidad. Londres, Amnistía Internacional.

ARRIETA, P. (1999): «El pensamiento de Aguirre Beltrán respecto a la autonomía indígena», Sotavento, $\mathrm{n}^{\circ}$ 5, pp.197-205.

ASCENCIO CEDILLO, E., LÓPEZ MOYA, M., y RUÍZ TORRES, M. (2011): «Consumidores alternativos: turismo étnico y espiritualidad new age en los procesos de reinvención del imaginario urbano en San Cristóbal de las Casas, México», Pasos. Revista de Turismo y Patrimonio Cultural, vol. V, pp. 289-305.

BABB, F. (2011): «Remembering the Revolution: Indigenous Culture y Zapatista Tourism», en The Tourism Encounter. Fashioning Latin American Nations y Histories. F. Babb. Stanford, Stanford University Press, pp. 92-120.

BARONNET, B. (2009): Autonomía y educación indígena: Las escuelas zapatistas de las Cañadas de la Selva Lacandona de Chiapas, México. Tesis de Doctorado en Ciencia Social, con especialidad en Sociología, El Colegio de México, México.

BARTRA, R. (1992): El Salvaje en el espejo. Ciudad de México, UNAM, Ediciones Era. BELTRÁN DEL RÍO, P. (1999): «Amenazas de expulsión, interrogatorios arbitrarios y restricciones migratorias», Revista Proceso, Edición 15 de mayo de 1999.

CAÑAS, S. (2016): «Pueblo trágico: gubernamentalidad neoliberal y multicultural en el sureste mexicano», Pueblos y fronteras digital, vol. 11 (21), pp. 3-30.

CASTELLANOS, A. (2001): «Tolerancia, racismo y pueblos indios de México» en Memoria del Seminario Internacional sobre tolerancia. México, CNDH.

CASTRO SOTO, G. (2000): «Las Fuerzas Armadas en Chiapas», en Siempre cerca, siempre lejos. Las Fuerzas Armadas en México. México, Global Exchange - CIEPAC - CENCOS, pp. 109-135.

CIDH (2016): Informe No. 51/16, Caso 11.564. Gilberto Jiménez Hernández y otros (La Grandeza). México, Comisión Interamericana de Derechos Humanos, OEA. OEA/ Ser. L/V/II.159.

COMITÉ PROMOTOR DEL DESARROLLO SOCIOECONÓMICO DEL ESTADO (1979): Plan Chiapas - Turismo. Primera Etapa Operativa Anual México. México, Comité Promotor del Desarrollo Socioeconómico del Estado.

CORONADO, G. (2008): «Insurgencia y turismo: reflexiones sobre el impacto del turista politizado en Chiapas», Pasos, Revista de Turismo y Patrimonio Cultural, vol. 6 (1), pp. 53-68.

CPEUM (1917): Constitución Política de los Estados Unidos Mexicanos. México, Diario Oficial de la Federación. 
DE LA GRANGE, B. y RICO, M. (2005): Marcos, la genial impostura. México D. F., Ediciones Cal y arena.

DE LA PEÑA, M. (1951): Chiapas económico. Tuxtla Gutiérrez, México, Departamento de Prensa y Turismo.

DE VOS, J. (2002): Una tierra para sembrar sueños. Historia reciente de la Selva Lacandona, 1950-2000. México, FCE, CIESAS.

DECROP, A. (1999): Triangulation in qualitative tourism research. Namur, Belgium, Department of Business Administration, University of Namur.

EARLE, D. y SIMONELLI, J. (2005): Uprising of Hope. Sharing the Zapatista Journey to Alternative Development. USA, Altamira Press.

EZLN (1994a): Primera Declaración de la Selva Lacandona. Chiapas, México. Disponible en http://palabra.ezln.org.mx/comunicados/1994/1993.htm

EZLN (1994b): Postdatas de comunicado del Subcomandante Marcos, 28 de mayo de 1994. Disponible en http://www.bibliotecas.tv/chiapas/may94/28may94.html

EZLN (2003): Chiapas: la treceava estela. Disponible en: http://palabra.ezln.org.mx/ comunicados/2003/2003_07_a.htm

EZLN (2013): Cuadernos de texto de primer grado del curso «La Libertad según l@s Zapatistas». México.

FOLEY, M. y LENNON, J.J. (1996): «Heart of darkness», International Journal of Heritage Studies, vol. 2 (4), pp. 195-197.

FRAYBA (1998): Acteal: entre el Duelo y la Lucha. San Cristóbal de las Casas, Centro de Derechos Humanos Fray Bartolomé de Las Casas.

FRAYBA (2001): De la Memoria a la Esperanza. Informe Anual 2000. San Cristóbal de las Casas, Centro de Derechos Humanos Fray Bartolomé de Las Casas.

FRAYBA (2017): Manual para observadores de Derechos Humanos. San Cristóbal de las Casas, Centro de Derechos Humanos Fray Bartolomé de las Casas, AC.

GARZA TOVAR, J.R. (2009): Organización territorial del turismo en San Cristóbal de las Casas, Chiapas, México. Ciudad de México, Universidad Nacional Autónoma de México.

GARZA TOVAR, J. y SÁNCHEZ CRISPÍN, Á. (2015): «Estructura territorial del turismo en San Cristóbal de las Casas, Chiapas, México», Cuadernos de Turismo, no 35, pp. 185-209.

GIL OLMOS, J. (2014): Los reporteros mexicanos en la guerra zapatista. Saarbrücken, Alemania, Editorial Redactum.

GLOBAL EXCHANGE (1999): Foreigners of Conscience: The Mexican Government's Campaign Against International Human Rights Observers in Chiapas. México, Global Exchange/Red de derechos humanos "Todos los derechos para todos"/Centro de Derechos Humanos Miguel Agustín Pro. Juárez/Comisión Mexicana para la Defensa y Promoción de los Derechos Humanos.

GONZÁlEZ CASANOVA, P. y CADENA ROA, J. (1994): La República Mexicana: modernización y democracia de Aguascalientes a Zacatecas. México D. F., UNAM.

GUTIÉRREZ LUNA, D.I. (2012): «De las luchas agrarias, a las luchas por otro mundo posible: El caso de los territorios liberados del "mal gobierno" en Chiapas, México», El otro derecho, pp. 243-268. 
HARVEY, D. (2003): Espacios de esperanza. Madrid, Akal.

HARVEY, N. (2000): La rebelión de Chiapas: la lucha por la tierra y la democracia. México, Editorial Era.

HIERNAUX, D. (2006): «Geografía del turismo» en A. Lindón and D. Hiernaux (Comps.) Tratado de Geografía Humana. México D. F., UAM Iztapalapa. Div. Ciencias Sociales y Humanidades, pp. 401-432.

HOUTART, F. (2013): Los zapatistas siguen existiendo. Disponible en: http://www.rebelion.org/noticia.php?id=166989

HRW (1997): Implausible deniability. State Responsibility for Rural Violence in México Human Rights Watch. USA.

INEGI (1984-2017): Anuario estadístico y geográfico de Chiapas. Aguascalientes, México, Instituto Nacional de Estadística, Geografía e Informática, INEGI.

INEGI (2004): La Población Hablante de Lengua Indígena de Chiapas. Aguascalientes, México, Instituto Nacional de Estadística, Geografía e Informática, INEGI.

INM (1998): CIRCULAR número INM/001/98 en la que se detallan las reglas a las que se sujetará el permiso de internación para visitantes miembros de organizaciones no gubernamentales interesados en conocer in situ la vigencia de los derechos humanos en México. México, Diario Oficial de la Federación.

JANZEN, C., JEFFERY, D., ET AL. (2015): Unravelling Encounters: Ethics, Knowledge, y Resistance Under Neoliberalism. Ontario, Canada, Wilfrid Laurier University Press.

LE BOT, Y. (1997): El sueño Zapatista. Barcelona, España, Editorial Anagrama.

LEFEBVRE, H. (2013): La producción del espacio. Madrid, Capitán Swing.

LEGORRETA DÍAZ, M.D.C. (1998): Religión, política y guerrilla en las Cañadas de la Selva Lacandona. México, Cal y Arena.

LEYVA SOLANO, X. (2009): «Nuevos procesos sociales y políticos en América Latina: las redes neozapatistas», en Repensar la política desde América Latina. Cultura, Estado y movimientos sociales. Lima, Perú, Programa Democracia y Transformación Global, Fondo Editorial de la Facultad de Ciencias Sociales, UNMSM.

LEYVA SOLANO, X. y BURGUETE, A. (2007): La remunicipalización de Chiapas. Lo político y la politica en tiempos de contrainsurgencia. México, UAM Iztapalapa; CIESAS; Porrúa.

LEYVA SOLANO, X. y ASCENCIO FRANCO, G. (2002): Lacandonia al filo del agua. México D. F., CIESAS, Fondo de Cultura Económica.

LÓPEZ MONJARDIN, A. y REBOLLEDO MILLÁN, D. M. (1999): «Los municipios autónomos zapatistas», Revista Chiapas, número 7, ERA-IIEc/ UNAM.

MARÍN, C. (1998): «Plan del Ejército en Chiapas, desde 1994: crear bandas paramilitares, desplazar a la población, destruir las bases de apoyo del EZLN», Proceso. Semanario de Información y Análisis, $\mathrm{n}^{\circ}$ 1,105, 4 de enero, México, CIS.

MARTÍNEZ ESPINOZA, M.I. (2006): «Las juntas de buen gobierno y los caracoles del movimiento zapatista: fundamentos analíticos para entender el fenómeno», RIPS. Revista de Investigaciones Políticas y Sociológicas, volumen 5, número 1, pp. 215 233.

MATTIACE, S., HERNÁNDEZ, R. y RUS, J. (2002): Tierra, libertad y autonomía: impactos regionales del zapatismo en Chiapas. México D.F., CIESAS - IWGIA. 
NOY, C. (2008): «Sampling Knowledge: The Hermeneutics of Snowball Sampling in Qualitative Research», International Journal of Social Research Methodology, vol. 11 (4), pp. 327-344.

PARÍS, M. D (2000) «Identidades excluyentes en San Cristóbal de las Casas», Nueva Antropología. Revista de Ciencias Sociales, $\mathrm{n}^{\circ}$ 58, pp. 81-93.

PITTS, W. J. (1996): «Uprising in Chiapas, Mexico: Zapata lives - tourismfalters», en Tourism, Crime y International Security Issues. A. Pizam y Y. Mansfeld. New York, Wiley, pp. 215-227.

RAFFESTIN, C. (2013): Por una geografía del poder. Michoacán, México, El Colegio de Michoacán.

REBÓN, J. (2001): Conflicto armado y desplazamiento de población: Chiapas 1994-1998. México, D.F., FLACSO.

ROVIRA, G. (2009): Sin fronteras. Las redes de solidaridad con Chiapas y el altermundismo. Ciudad de México, Ediciones Era.

SCHERER IBARRA, M. y LÓPEZ, J.C. (2000): «Son cuestionadas por los propios tribunales mexicanos. Extranjeros en Chiapas: las expulsiones dudosas», Proceso. Semanario de Información y Análisis, número 1.210, 8 de enero, México, CIS.

SECRETARÍA DE EDUCACIÓN Y CULTURA (1984): San Cristóbal y sus alrededores. Tuxtla Gutiérrez, Secretaría de Educación y Cultura, Gobierno de Chiapas.

SEDENA (1994): Plan de campaña Chiapas 94. Tuxtla Gutiérrez, Secretaría de la Defensa Nacional

SIPAZ (2006): SiPaz. 10 Años de presencia internacional y trabajo para la Paz en Chiapas. San Cristóbal de las Casas, México, SIPAZ.

SPRADLEY, J.P. (1980): Participant Observation . Florida, Estados Unidos, Holt, Rinehart and Winston.

URRY, J. (2002): The Tourist Gaze. London, SAGE Publications.

VAN BROECK, A. y LÓPEZ, A. (2018): «Turismo oscuro. De la conmemoración a la comodificación de la muerte, los desastres y lo macabro». Teoría y Práxis, no 24, pp. 23-68.

VAN DEN BERGHE, P. y KEYES, C. (1984): «Introduction: tourism and re-created ethnicity» Annals of Tourism Research, vol. 11, pp. 343-352.

VOLPI, J. (2004): La guerra y las palabras. México D.F., Ediciones Era.

PHYSICIANS FOR HUMAN RIGHTS y HRW (1994): México: Waiting for Justice in Chiapas. Estados Unidos, Physicians for Human Rights \& Human Rights Watch/ Americas.

\subsection{Entrevistas}

ADRIANA (2017): Empresaria turístico, propietaria de hotel del centro de la ciudad. Realizada en San Cristóbal de las Casas, 26 de mayo de 2017.

ALEXANDER (2016): Empresario turístico, propietario de hostal. Realizada en San Cristóbal de las Casas, 20 de julio de 2016.

ASCENCIO, G. (2017): Académico de CIMSUR, UNAM, San Cristóbal de las Casas, 12 de mayo de 2017. 
DOMÍNGUEZ, A. (2017): Empresario turístico, propietario de Centro cultural y restaurant. Realizada en San Cristóbal de las Casas, 22 de mayo de 2017.

EMPRESARIO (2016): Empresario turístico, propietario de Hotel Santa Clara. Realizada en San Cristóbal de las Casas, 16 de julio de 2016.

GONZÁLEZ, D. (2017): Miembro de SERAPAZ. Realizada en Ciudad de México, 3 de mayo de 2017.

GONZÁLEZ, G. (2016): Académico de Ecosur. Realizada en San Cristóbal de las Casas, 15 de julio de 2016.

GUÍA 1 (2017): Guía turístico. Realizada en tour a Lagunas de Montebello, Chiapas, 22 de mayo de 2017.

GUÍA 2 (2017): Guía turístico. Realizada en tour Palenque-Bonampak, Chiapas, 21 de julio de 2017.

GUÍA 3 (2017): Guía turístico. Realizada en San Cristóbal de las Casas, 12 de mayo de 2017.

GUTIÉRREZ, C. (2017): Académico CIDSUR, UNAM. Realizada en San Cristóbal de las Casas, 7 dejulio de 2017.

HERNÁNDEZ (2017): Observador de DDHH, miembro del Centro de Derechos Humanos Frayba. Realizada en San Cristóbal de las Casas, 25 de mayo de 2017.

JBG (2017): Miembros de la Junta de Buen Gobierno. Realizada en Caracol de Oventik, 29 de julio de 2017.

JOSÉ (2017): Encargado de personal de Restaurant Tierradentro. Realizada en San Cristóbal de las Casas, 25 de mayo de 2017.

MORALES, M. A. (2016): Funcionario de SECTUR Chiapas. Entrevista realizada en Tuxtla Gutiérrez, 22 de julio de 2016.

MORALES, M. A. (2017): Funcionario de SECTUR Chiapas. Entrevista realizada en Tuxtla Gutiérrez, 3 de julio de 2017.

MORQUECHO, G. (2016): Periodista del periódico “El Tiempo" durante el levantamiento zapatista. Realizada en San Cristóbal de las Casas, 15 de julio de 2016.

RAMOS, C. (2017): Miembro de Otros Mundos A.C., 24 de mayo de 2017.

RUÍZ, M. (2017): Dirigente indígena. Realizada en San Cristóbal de las Casas, 17 de mayo de 2017.

SUSANA (2017): miembro del Centro de Derechos Humanos Frayba. Realizada en San Cristóbal de las Casas, 24 de mayo de 2017.

ULISES (2016): Académico de institución superior de Chiapas. Realizada en San Cristóbal de las Casas, 14 de julio de 2016. 